\title{
A rare case of subungual exostosis of the hallux in an adolescent-a clinico-pathological review of literature
}

\author{
Supreeth Nekkanti*, Arunodhaya Siddartha, Sujana Theja, Vijay C and Abhilash Gowd \\ Department of Orthopedics, JSS Medical University and Hospital, Mysore, Karnataka, India
}

\begin{abstract}
Osteochondromas and subungual exostosis are commonly misunderstood conditions. They are widely used synonymously. However a detailed review of literature tells us that subungual exostosis is in fact a rare variant of osteochondroma. This peculiar tumor is relatively uncommon; it has not been much remarked on the recent years. We report a case of subungual exostosis of the hallux in an 18 year old girl who presented to us with a swelling on her great toe which ulcerated the skin and caused lifting of the nail. We surgically excised the mass and reconstructed the nail and confirmed the diagnosis by histopathological studies. We present this case for its rarity and also because it is often misunderstood and misdiagnosed.
\end{abstract}

\section{Introduction}

Osteochondromas are benign bone tumors of the foot commonly occurring in the phalanges [1]. Subungual exostosis (SE), however is uncommon benign bone tumor arising in the distal phalanx of the digit, typically originating from or around the nail bed. It is considered a rare variant of osteochondroma [2]. Dupuytren G in 1847 first described this enitity in his study of 30 patients suffering from subungual exostoses of the great toe $[3,4]$. These two entities are often confused to be the same and many a time misdiagnosed. There is very limited literature that explains the difference between these two conditions. The authors attempt to explain the subtle differences between these two tumors with a comprehensive review of literature.

\section{Case report}

We report a18 year old female who presented to us with a swelling of the great toe in the last 4 months. It was sudden in onset and gradually progressive. The growth of the swelling led to ulceration of the overlying skin and nail. The mass also caused deformity of the overlying nail. On clinical examination, a $2 \times 2 \times 2 \mathrm{~cm}$ oval swelling was observed over the dorsomedial aspect of the tip of the great toe. The swelling had grown through the overlying skin and nail causing a bleeding ulcer over the great toe. The mass was hard and fixed to the bone.

Radiography: X-ray of the foot in antero-posterior and oblique views was done. It revealed a bony growth from the dorso-medial aspect of the distal phalanx of the great toe with a radiolucent cartilaginous cap. (Figure 1) A provisional diagnosis of osteochondroma of the distal phalanx of great toe was made.

Surgery: A curvilinear incision was made over the dorsomedial aspect of skin of the great toe extending over the tip of the great toe. The ulcerated margins were excised. The mass was identified and borders demarcated. The mass was then excised and remnant nibbled out. The consistency of the mass was not hard as expected in an osteochondroma. The mass was sent for histopathological studies. The surgical wound was repaired in layers and healthy nail was sutured back to the nail matrix. (Figure 2) Post-operative X-rays (Figure 3) showed that the tumor had been completely excised.

Histopathology: Epidermis showed neutrophil infiltration. Circumscribed delineated lesion composed of mature cartilaginous tissue with clustered chondrocytes in a myxoid stroma. Features were suggestive of chondroma. We reached a diagnosis of subungual exostosis of the distal phalanx of the great toe. The post-operative period was uneventful and sutures were removed on the tenth postoperative day (Figure 4).

\section{Discussion}

Subungual Exostosis (SE) is an uncommon bone tumor arising from the distal phalanx, classically from or around the nail bed. It has been described as a rare form of osteochondroma [4,5]. This tumor has

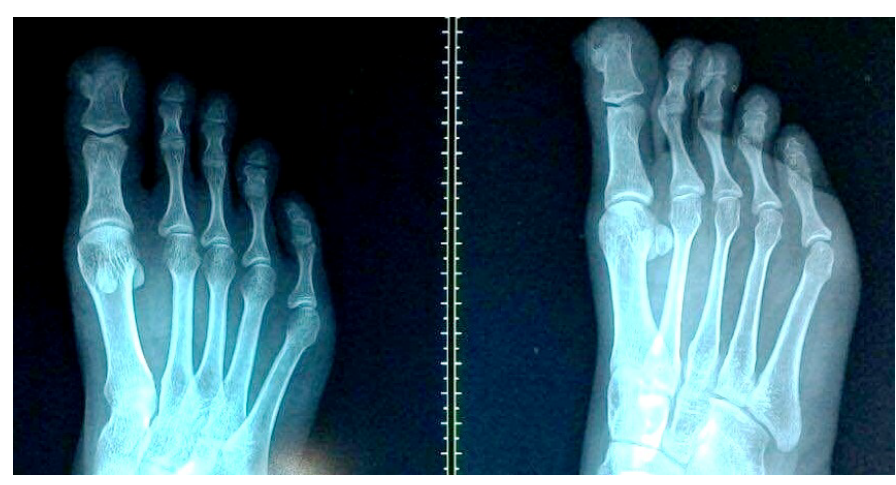

Figure 1. Pre-operative X-ray.

Correspondence to: Supreeth Nekkanti, Senior Resident, Department of Orthopedics, JSS Medical University and Hospital, Mysore, Karnataka, India, Tel: 919742551646; E-mail: drsupreethn@gmail.com

Key words: subungual exostosis, hallux, osteochondroma, misdiagnosis

Received: September 27, 2016; Accepted: December 22, 2016; Published: December 27, 2016 


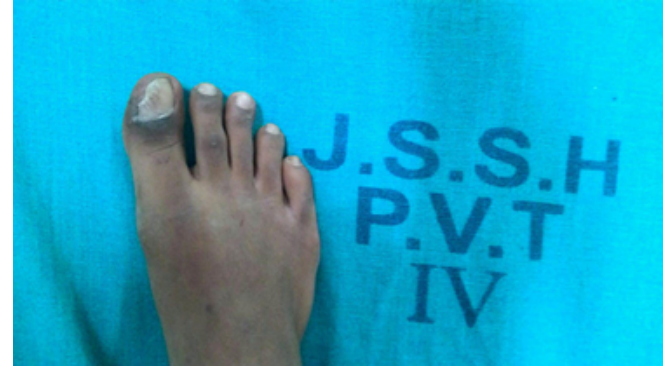

Figure 2. Post-operative clinical photograph.

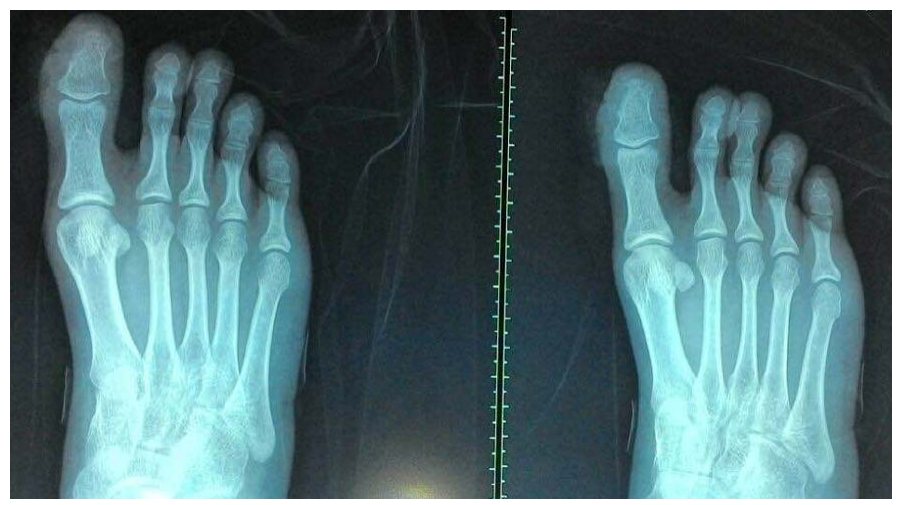

Figure 3. Post operative X-ray.

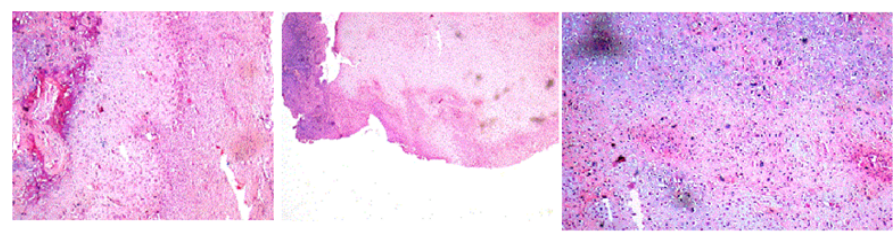

Figure 4. Histopathology images.

a predilection to involve the inner border of the distal phalanx of the great toe, but other toes and even fingers may also be affected [6-9]. These entities differ from the conventional exostoses, by the fact that they don't originate from the base of the distal phalanx adjacent to epiphyseal growth plate [6].

Subungual exostosis usually occurs in adolescents. It has been studied to have a predilection for females compared to males [5]. As was the case, our patient was a female patient in her adolescence, 18 years old when she presented to us with the complaints.

Clinical examination of these cases reveal typically a solitary lesion, which appears like a small firm lesion, usually located deep to the growing end of the nail. Pain, particularly occurs on walking, due to the friction between the nail plates with the expanding exostosis. The overlying nail is pushed up and is finally separated from the nail bed exposing a mass of fibrous tissue whose surface may become eroded and infected. This fibrous mass overlies the exostosis [5]. Our patient presented to us with 4 month history of the mass, which she ignored initially. After 4 months of daily activity it progressed to the present size and ulcerated the overlying skin and pushing up of the nail.

To explain the differences in presentation, García Carmona et al. [10] proposed a clinical classification scheme based on the clinical signs and symptoms present during examination and the associated disorders of the nail plate, progressing in severity from type 1 (mild deformity) to type 4 (medial or lateral condyle). Type 1 deformities are caused by normal or minimal incurvation of the nail plate. Type 2 deformities are a progression of type 1 in which the exostosis is distal to the nail plate. A type 3 deformity is associated with exostosis that is under the nail plate. Type 4 deformities are classified as osseous proliferations of either the medial or lateral condyles of the distal phalanx [10]. Using this classification system, our patient's nail would be classified as a type 2 deformity.

The pathogenesis of subungual exostosis is not clearly understood in the literature. It has been attributed to be a multifactorial problem. Trauma, chronic infection, tumor, hereditary abnormality has been commonly described causes in the reviewed literature [1]. Trauma is often described as a catalyst which leads to cartilaginous metaplasia resulting in a subungual exostosis. It also may develop following acute or chronic irritation $[4,6]$. Other studies have postulated that possible etiologies include teratologic abnormalities, form a part of multiple hereditary exostoses, activation of a cartilaginous cyst, or defect in the perichondrial node of Ranvier [1,3]

In the initial stages of development, the lesion appears as proliferating fibroblasts in direct continuity with the nail bed where cartilaginous metaplasia can be seen. The cartilage gradually undergoes calcification and ossifies. Later, the areas of enchondral ossification eventually progress to woven bone and then lamellar bone. In the early stage, proliferation of cartilage contributes to the exophytic growth of the lesion while later mature bone dominates the outgrowth [8]. Our patient might probably have presented to us in the initial phase of cartilage metaplasia.

Radiographically, an exostosis is seen as a bony outgrowth from the dorsal or dorso-medial aspects of the distal aspect of a terminal phalanx. It appears as a mature trabeculated bony outgrowth attached to the phalanx. The growing end is flat, cupped and smooth, or irregular. Unlike the clinical complaints, the radiological findings are subtle due to the presence of a large radiolucent cartilaginous cap [11]. There is no cortical disruption or other abnormality of the distal phalanx [2]. Our patient's radiographs were comparable with the literature in the sense of a small bony outgrowth of the distal phalanx surrounded by a large radiolucent cartilaginous cap.

Histologically, the immature lesion only has a thick fibrocartilaginous cap, responsible for the growth of the lesion $[3,4,8,9]$. The mature lesion consists of a base of trabecular bone with a proliferating fibrocartilaginous cap, [12] thereby differentiating SE from osteochondroma, which has a cartilaginous cap that consists of hyaline cartilage [8]. Subungual exostosis is hypercellular and the cartilage cells may have plump nuclei. However, the lack of anaplasia and its distinct radiographic appearance differentiate SE from chondrosarcoma. Malignant degeneration of subungual exostosis has not been reported $[3,4]$. The histological studies from the sample obtained in our patient showed clusters of cartilaginous cells with minimal osteoid tissue suggesting a diagnosis of subungual exostosis of the distal phalanx of great toe.

The clinical presentation leads SE to be easily misdiagnosed, which may result in inadequate or extreme treatments. The histological and radiologic findings make SE distinct. The differential diagnosis of subungual exostosis includes subungual verruca, granuloma pyogenicum, glomus tumor, carcinoma of the nail bed, enchondroma, and ingrown toe nail [2]. Osteochondroma, enchondromas are cartilaginous tumors arising in the medullar cavity of tubular bones and should not be misdiagnosed as SE. 
Surgical excision is the most appropriate treatment; when correctly performed; long-lasting results are obtained [5]. Recurrence rates vary from $11 \%$ to $53 \%$; $[13,14]$. However, if the lesion base is excised at the cortex until spongy bone is observed, recurrence rates drop to $5 \%$ to $11 \%[9,15]$. We have followed up our patient for 18 months and she is absolutely fine with no evidence of recurrence.

We report this case for its rarity and it being a common cause for misdiagnosis. It is critical for clinicians to identify this condition clinically and to confirm by radiography and histopathological studies. This reduced unwarranted under or over treatment of this condition and thereby reduces risk of recurrence. Special care must be taken not to extensively damage the nail matrix while excising this tumor.

\section{Conclusion}

Subungual exostosis is a benign fibrocartilaginous tumor arising from the terminal phalanx that is rarely seen in clinical practice. It should be considered as a differential when diagnosing various finger/ toe tip pathologies. The subungual exostosis occurs due to repeated trauma in the nail bed which leads to cartilage metaplasia followed by its ossification. Without the nail protection, the nail blade is exposed to the infection and hence it must be removed at the earliest. In the absence of the supporting histopathological and radiographic evidence, patients may be misdiagnosed and treatment ineffective. The local excision and the removal of the cartilaginous cap is the elective treatment of the subungual exostosis.

\section{References}

1. Tuzuner T, Kavak A, Parlak AH, Ustundag N (2006) Subungual osteochondroma: a diagnostic dilemma. J Am Podiatr Med Assoc 96: 154-157. [Crossref]
2. Ilyas W, Geskin L, Joseph AK, Seraly MP (2001) Subungual exostosis of the third toe. J Am Acad Dermatol 45: S200-201. [Crossref]

3. Dupuytren G (1847) In: Clark F (ed) On the injuries and diseases of the bones, Publications of the Sydenham Society, London 1847: 408-410.

4. Landon GC, Johnson KA, Dahlin DC (1979) Subungual exostoses. J Bone Joint Surg Am 61: 256-259. [Crossref]

5. Aggarwal K, Gupta S, Jain VK, Mital A, Gupta S (2008) Subungual exostosis. Indian J Dermatol Venereol Leprol 74: 173-174. [Crossref]

6. Landon GC, Johnson KA, Dahlin DC (1979) Subungual exostoses. J Bone Joint Surg Am 61: 256-259. [Crossref]

7. Shaffer LW (1931) Subungual exostoses. Arch Dermatol Syph 24: 371-379.

8. Dave S, Carounanidy U, Thappa DM, Jayanthi S (2004) Subungual exostosis of the thumb. Dermatol Online J 10: 15. [Crossref]

9. Dawber RPR, Baran R, De Berker D (1998) Disorders of nails. Rook/Wilkinson/Ebling Textbook of Dermatology, 6th edition, Volume 4, Blackwell Science, Oxford.

10. García Carmona FJ, Pascual Huerta J, Fernández Morato D (2009) A proposed subungual exostosis clinical classification and treatment plan. J Am Podiatr Med Assoc 99: 519-524.

11. Carroll RE, Chance JT, Inan Y (1992) Subungual exostosis in the hand. J Hand Surg $\operatorname{Br}$ 17: 569-574. [Crossref]

12. Dave S, Carounanidy U, Thappa DM, Jayanthi S (2004) Subungual exostosis of the thumb. Dermatol Online J 10: 15. [Crossref]

13. Murphey MD, Choi JJ, Kransdorf MJ, Flemming DJ, Gannon FH, et al. (2000) Imaging of osteochondroma: variants and complications with radiologic-pathologic correlation. Radiographics 20: 1407-1434.

14. Bahnassy M, Abdul-Khalik H (2009) Soft tissue chondroma: a case report and literature review. Oman Med J 24: 296-299. [Crossref]

15. Enzinger FM, Weiss SW (2008) 8th edn. Soft tissue tumors. CV Mosby co. St. Louis.

Copyright: (C2016 Nekkanti S. This is an open-access article distributed under the terms of the Creative Commons Attribution License, which permits unrestricted use, distribution, and reproduction in any medium, provided the original author and source are credited. 